\title{
The Role of the Physician When a Patient Discloses Intimate Partner Violence Perpetration: A Literature Review
}

\author{
Brian Penti, MD, MS, Joanne Timmons, MPH, and David Adams, EdD
}

\begin{abstract}
Intimate partner violence (IPV) is prevalent and has lasting impacts on the health and well-being of the entire family involved. Primary care physicians often interact with male patients who perpetrate IPV and are in a role potentially to intervene, but there is very little research and guidance about how to address perpetration of IPV in the health care setting. We reviewed the existing literature research related to physicians' interactions with male perpetrators of IPV and summarize the recommendations. If a male patient discloses IPV perpetration, physicians should assess for lethality, readiness to change, and comorbid medical conditions that could impact treatment, such as substance abuse and mental illness. Experts agree that referrals to a Batterer Intervention Program should be the primary intervention. If there are no locally available Batterer Intervention Programs or the patient is unwilling to go, then a physician should refer the abuser to a therapist who has been trained specifically to work with perpetrators of IPV. In addition, physicians should be prepared to offer education about the negative impact of IPV on the victim, on any children, and on the abuser himself. Physicians should address any untreated substance abuse or mental health issues. Referral to couples therapy should generally be avoided. Physicians should continue to have regular follow-up with their male patients to support them in changing their behavior. Further research is needed to assess the role the health care system can have in preventing IPV perpetration. (J Am Board Fam Med 2018;31:635-644.)
\end{abstract}

Keywords: Intimate Partner Violence, Primary Care Physicians, Spouse Abuse

Intimate partner violence (IPV) is defined by the US Centers for Disease Control and Prevention as physical violence, sexual violence, stalking, and psychologic aggression by a current or former partner or spouse. ${ }^{1}$ Beyond the types of violence involved, IPV is generally recognized as a pattern of coercive control on the part of the abuser that serves to undermine the victim's will or autonomy. ${ }^{1}$ Multiple theoretic models exist to explain IPV, including feminist ${ }^{2}$, power ${ }^{3}$, social learning ${ }^{4}$, ecologic ${ }^{5}$, and psychoanalytic theories ${ }^{6}$, although empirical data

This article was externally peer reviewed.

Submitted 13 November 2017; revised 26 January 2018; accepted 9 February 2018.

From Department of Family Medicine Boston, Boston University School of Medicine, MD (BP); Boston Medical Center, Boston (JT); Emerge, Cambridge, MA (DA).

Funding: none.

Conflict of interest: none declared.

Corresponding author: Brian Penti, MD, MS, 1 Boston Medical Center Plaza, Dowling 5 South, Boston, MA 02118 (E-mail: bpenti93@gmail.com). to support these models is often lacking ${ }^{7}$, hence many researchers conclude that IPV results from a combination of individual, household, community, and societal factors. ${ }^{5,8}$

Every year in the United States, there are approximately 5 million incidents of IPV that involve female victims, ${ }^{9}$ resulting in 1,200 deaths and more than 250,000 injuries. ${ }^{10}$ In addition, these incidents entail economic costs to the health care system as well as to employers in terms of lost productivity. In 1995 , these costs exceeded $\$ 8.3$ billion. ${ }^{11}$ Moreover, 1 in 4 children in the United States witness parental IPV during their lifetime and approximately 1 of every 15 children witness episodes on a yearly basis. ${ }^{12}$ The impact of IPV on the health and mental well-being of survivors and children is significant and long-lasting (Table 1) ${ }^{13-18}$, and there are negative impacts on the perpetrator. ${ }^{19-21}$

The United States Preventive Task Force recommends screening women of childbearing age for 


\begin{tabular}{|c|c|}
\hline Impact on Victim $^{13,14}$ & $\begin{array}{l}\text { Associated with the following: } \\
\text { - Poor pregnancy outcomes } \\
\text { - Depression, post-traumatic stress disorder, and suicide } \\
\text { - Increased risk for job loss } \\
\text { - Increased mortality } \\
\text { - Chronic pain } \\
\text { - Neurologic symptoms (fainting, seizures) } \\
\text { - Gastrointestinal symptoms (eating disorders, irritable bowels) } \\
\text { - High blood pressure } \\
\text { - Gynecologic problems (pelvic pain, sexually transmitted } \\
\text { diseases) }\end{array}$ \\
\hline $\begin{array}{l}\text { Impact on Children Witnessing Intimate Partner } \\
\text { Violence at Home }{ }^{15,16,17,18}\end{array}$ & $\begin{array}{l}\text { Associated with the following: } \\
\text { - Depression and anxiety } \\
\text { - Substance problems as adults } \\
\text { - Risky sexual behavior amongst adolescent girls } \\
\text { - Poor school performance } \\
\text { - Emotional and behavioral problems } \\
\text { - Poor overall health as adult (ACE studies) } \\
\text { - Somatic complaints such as headaches, sleep problems, } \\
\text { stomach aches } \\
\text { - Boys may be violent as adults and girls may not question } \\
\text { violence used against them as adults }\end{array}$ \\
\hline Impact on Perpetrator ${ }^{19,20,21,28}$ & $\begin{array}{l}\text { Associated with the following: } \\
\text { - Regret and depression } \\
\text { - Poor job performance } \\
\text { - Incarceration and other legal problems } \\
\text { - Divorce and separation from family } \\
\text { - Physical injuries } \\
\text { - Substance abuse } \\
\text { - Psychiatric disease } \\
\text { - High-risk sexual behavior } \\
\text { - Insomnia } \\
\text { - Digestive problems }\end{array}$ \\
\hline
\end{tabular}

ACE, adverse childhood experiences.

IPV victimization based on evidence of the effectiveness of screening and of the lack of harm. ${ }^{22}$ However, there has been only limited research conducted on the potential benefits and harms of screening men for IPV perpetration. Although men are also victims of IPV, the majority of IPV perpetrators are $\operatorname{men}^{10,23}$ and these men often access the health care system. According to prior studies, 13\% to $23 \%$ of male patients self-report having perpetrated IPV ${ }^{24-28}$ and 2 out of 3 male perpetrators report seeing a regular doctor for routine care. ${ }^{28}$

Although men often do not disclose their abusive behaviors during medical encounters, physicians may become aware that their male patients are IPV perpetrators in other ways, including disclosures by victims, documentation in medical records, and behavior directly disclosed or wit- nessed. ${ }^{29,30}$ Screening protocols for perpetration of IPV have been developed ${ }^{24-26,31}$ but, to our knowledge, screening for IPV perpetration is not commonly practiced and has not been recommended by any of the major medical societies.

The position article on violence issued by the American Academy of Family Physicians states that family physicians have a role both in recognizing perpetration of IPV and in providing appropriate referrals. ${ }^{32}$ Despite this statement, there has been very little research into this topic, leaving physicians unprepared to interact with male perpetrators of IPV. ${ }^{29}$ Pilot guidelines were developed by the Family Violence Prevention Fund (now known as Futures Without Violence), and other experts have offered their guidance on this topic ${ }^{30,31,33-39}$, but these are often based on expert opinion with limited evidence to 
Figure 1. Flow diagram of the search strategy used to identify guidelines and review articles related to primary care role in assessing and intervening with male perpetrators of intimate partner violence (IPV). The database search queried PubMed database from January 1990 through July 2017.

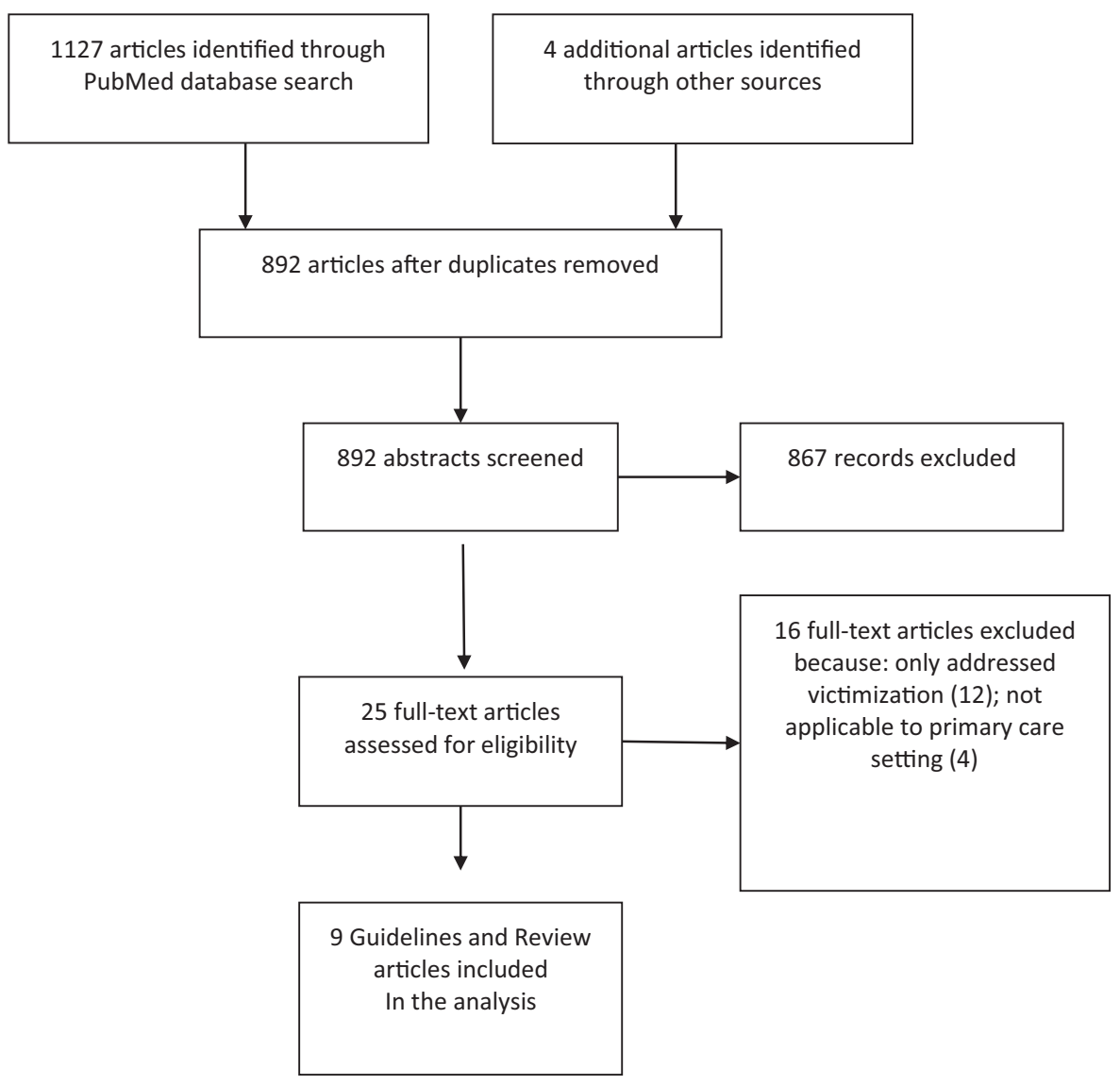

support them and have not, to our knowledge, been formally evaluated. This review article attempts to summarize the existing literature about what physicians should do when they find themselves interacting with a male patient who discloses IPV perpetration. Of note, men may also be victims of IPV in heterosexual relationships and IPV perpetration exists in LGBTQ relationships, but these are beyond the scope of this review. In addition, we do not discuss situations where a female victim discloses IPV, in confidence, to a physician who also cares for the male perpetrator, which is also beyond the scope of this article.

\section{Methods}

For this review, we searched PubMed by using the terms "intimate partner violence," "male perpetration," "domestic violence," and "guidelines" in multiple combinations. (Figure 1). The abstracts of these articles were reviewed and excluded if they were not in English, pertained only to victims of IPV, or were unrelated to clinical medicine. The remaining articles were then reviewed with a focus on the assessment of IPV perpetration and recommendations with respect to intervention with an IPV perpetrator. The reference sections of these articles were reviewed to find additional references. A total of 9 review articles or guidelines were identified (Table 2). Common themes and recommendations were identified and are summarized in Table 3. Additional research was done as needed to support or refute the recommendations or to provide additional background information. Strength of evidence was not assessed, as only a few of the recommendations, such as referring to Batterer Intervention Program (BIP), were based on existing research.

\section{Assessment}

The assessment of male IPV perpetration should only occur if the male patient discloses the IPV perpetration to the physician directly and should not be addressed if the physician learns of the perpetration from the victim, 
Table 2. Summary of Published Review Articles and Treatment Guidelines for Addressing Male Perpetration of Intimate Partner Violence

\begin{tabular}{|c|c|c|}
\hline Author/Year & Purpose & Description \\
\hline Adams D, $1996^{37}$ & Recommendations & Recommendations per expert in the field \\
\hline Cronholm PF, $2006^{34}$ & Review & Review article of existing literature \\
\hline Hegarty et al, $2016^{35}$ & Review & Recommendations per experts in the field \\
\hline Ferris et al, $1997^{36}$ & Guidelines & $\begin{array}{l}\text { Guidelines for when physician cares for both victim } \\
\text { and perpetrator of intimate partner violence, } \\
\text { developed by } 15 \text {-member expert panel }\end{array}$ \\
\hline Ganley E, $1998^{30}$ & Recommendations & Recommendations per expert in the field \\
\hline Kimberg LS, $2008^{31}$ & Guidelines & $\begin{array}{l}\text { Pilot guidelines developed by expert panel for Futures } \\
\text { Without Violence (previously known at Family } \\
\text { Violence Prevention Fund) }\end{array}$ \\
\hline Mintz HA, Cornett FW, $1997^{39}$ & Recommendations & Recommendations per experts in the field \\
\hline Gondolf, $1998^{38}$ & Recommendations & $\begin{array}{l}\text { Recommendations per expert in the field for mental } \\
\text { health providers }\end{array}$ \\
\hline RACGP, $2014^{33}$ & Guidelines & $\begin{array}{l}\text { White paper per the Royal Australian College of } \\
\text { General Practitioners }\end{array}$ \\
\hline
\end{tabular}

unless the victim specifically requests the physician to do so. Physicians should be aware that some perpetrators have a vested interest in creating the perception that they are the victim and may falsely state that they have been victimized or that their partner is to be blamed for the behavior. The physician will often be unable determine the truth in these situations; hence, it is important to seek consultation from an IPV specialist. Nonetheless, if a male patient discloses IPV perpetration, either in requesting help or during the history taking, then the physician should attempt to assess the following: the impact of the IPV on the entire family; comorbidities, such as substance abuse or mental illness; any immediate threats of harm to the victim or children; and the perpetrator's readiness to change.

\section{Impact of IPV on the Health of the Perpetrator, the Victim, and Any Children}

Physicians should explore the impact of IPV, both past and present, on the perpetrator's health. ${ }^{30,31,37}$

Table 3. Summary of Recommendations for Family Medicine Physicians and Other Primary Care providers When Assessing and Intervening with Male Perpetrators of Intimate Partner Violence in Primary Care Settings, from Published Guidelines and Review Articles

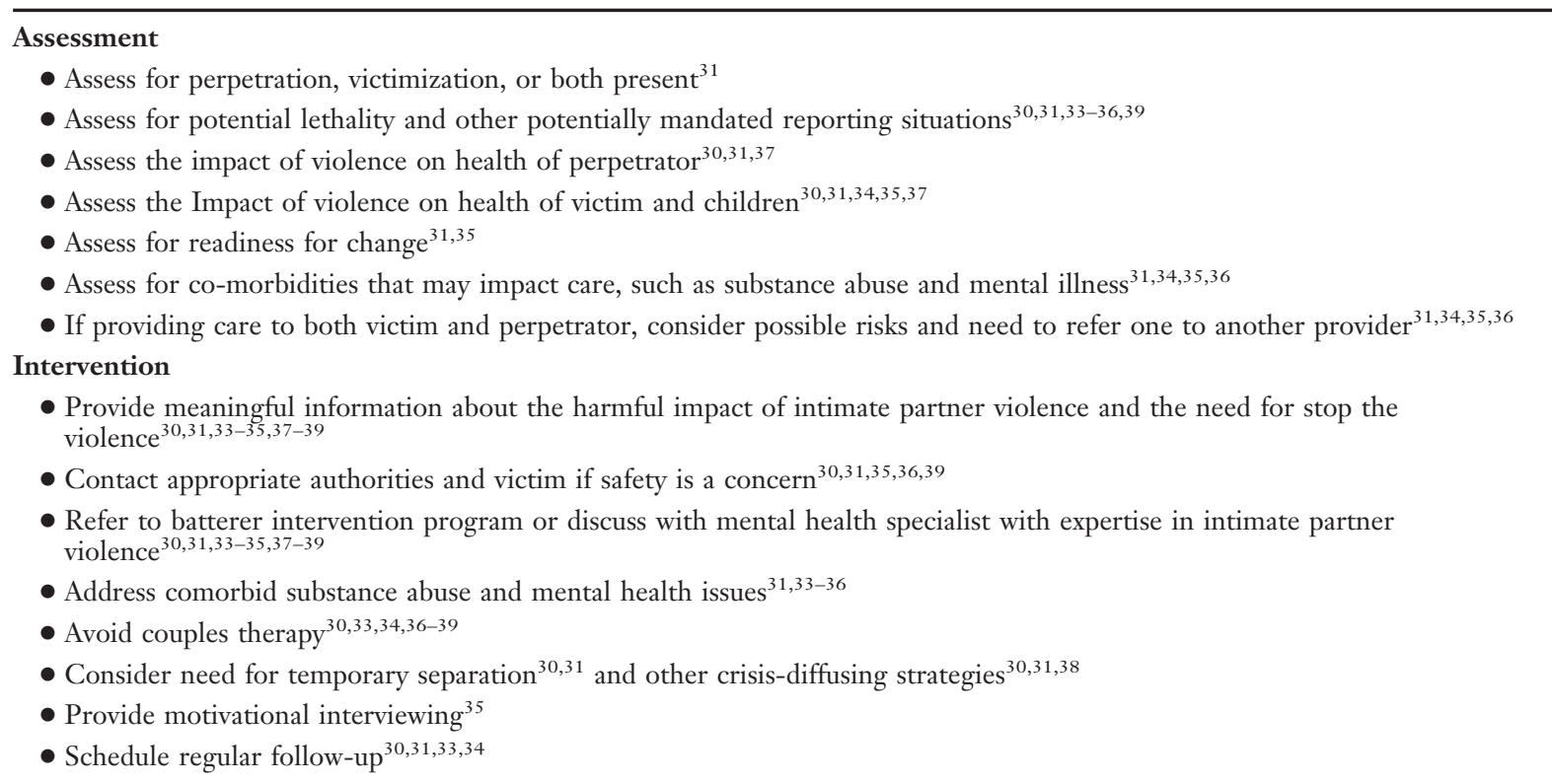


Table 4. Risk Factors for Femicide in Intimate Partner Violence ${ }^{52}$

- Perpetrator's access to gun

- Perpetrator's previous threats with a weapon or threats to kill

- Recent estrangement from a controlling partner

- Worse incident of abuse triggered by victim leaving abuser for another partner or by abuser's jealousy

- Perpetrator using illicit drugs

- Perpetrators threats of suicide

- Stalking behavior

Although there is limited research on the health impact of IPV perpetration on perpetrators, there are some studies that do demonstrate health problems associated with it, such as insomnia, chronic pain, injuries, and mental health problems (Table 1). ${ }^{19-}$ $21,28,40$ It should be noted that the direction of association is not known; one could potentially contribute to the other, or there could be additional factors associated with IPV contributing to both.

Physicians should ask perpetrators of IPV if they think the behavior is contributing to their health problems. In addition, physicians should ask about the health of the patient's partner and any children they may have, and if they think IPV has contributed to any of their health problems. ${ }^{30,31,33,34,37}$ This information may provide additional motivation for perpetrators to change their behavior, especially the potential impact it may have on any children. ${ }^{18,41-44}$

\section{Comorbidities}

Physicians should assess male perpetrators for comorbid medical problems, such as substance abuse and mental illness, both of which have been associated with IPV perpetration. ${ }^{45-49}$ Although the evidence does not suggest that substance abuse or mental illness specifically causes IPV perpetration, treatments to address IPV perpetration will be of limited effectiveness if co-occurring substance abuse and mental illness are not also addressed. ${ }^{46,49}$

\section{Readiness for Change}

The physician should assess readiness to change, as this may dictate the possible intervention to be provided. ${ }^{31,35}$ Physicians should specifically ask the man if he has ever felt a need to change his behavior and if he thinks his behavior is affecting his health or that of his family members. Assessing his level of readiness to change will help to determine if a patient is ready to accept a referral to address his problem or if he's precontemplative and needs more education about the impact of IPV perpetration.

\section{Severity of Violence}

Determining the severity of violence committed from the perpetrator can be difficult, because perpetrators often minimize or deny the violence. ${ }^{24,50,51}$ In addition, the abuser may consider himself a victim or there may be bidirectional violence. Furthermore, the physician may lack training, validated assessment tools, and time to do the assessment correctly. Nonetheless, the provider should attempt to assess the perpetrator for lethality. ${ }^{30,31,35,38}$ Although screening tools have been developed to assess the safety of victims of IPV in the health care setting (Table 4), ${ }^{52}$ most have not been designed for use with perpetrators of IPV. Considerations include the following: How serious have prior attacks been (eg, did they involve strangulation or use of weapons?); Does the perpetrator have imminent plans to hurt his partner and/or children? or Has he made threats to harm them?; and Does the perpetrator have access to a weapon? In addition, because men who are abusive to their partners are at increased risk for abusing and neglecting their children, ${ }^{18}$ physicians should clarify if there are children in the home and, if so, determine if they are at risk. ${ }^{31,34 \text {, }}$

\section{Intervention}

Physicians should work to engage the perpetrator in efforts to stop the IPV perpetration for a number of reasons. These include improving the health and safety of his intimate partner and any children, stopping the cycle of violence by preventing any children from becoming abusers as adults, avoiding legal consequences of his actions, and improving the health and well-being of the perpetrator himself. ${ }^{34}$ Discussing IPV perpetration as a health care issue and expressing concern for the health and 
well-being of the perpetrator allow the physician to encourage change in a nonjudgmental manner. ${ }^{31}$ The physician can potentially build a therapeutic alliance with that part of the male perpetrator that wants a better life for himself and his family, which at the same time may allow the physician to address any denial or minimization. ${ }^{35,53}$

\section{Providing Education}

Getting the individual to realize that IPV perpetration is a problem for which they are responsible is a necessary step in changing behavior. ${ }^{30,31,35,37,38}$ While not wanting to alienate the perpetrator, the physician should hold the perpetrator responsible for his actions and offer him support in ending the abusive behavior..$^{30,36,38}$ The abuser may blame his violence on outside influences, such as alcohol, stress, his partner, or an abusive childhood, but the physician should state clearly that the choice to use violence is ultimately his choice and is not acceptable. Some practitioners have found that this message is received less defensively when the focus is on the abusive action and not the person himself but that the abuse will not likely stop on its own without some intervention. ${ }^{30,35}$ Physicians should provide expert information about the considerable damaging effects of IPV on victims, children, and the perpetrators themselves (Table 1). Discussing the impact of IPV on any children may be particularly important in influencing a male perpetrator's behavior, as recent studies indicate that men do not want their children to be in fear or to be impacted because of witnessing IPV. ${ }^{41-44}$

\section{Addressing the Safety of the Victim and Mandating Reporting}

Physicians must be aware of their legal and ethical responsibilities to warn victims of violence (duty to warn) when there is a clear and present danger. ${ }^{30,31,35,36,38,39}$ In addition, physicians need to know the state mandatory reporting laws that apply, especially if there is concern about lethality. Concerns about lethality may require mental health commitment or law enforcement involvement. Legal precedents for duty to warn, mandating reporting, law enforcement interventions, and mental health commitments vary from state to state, hence Ganley $^{30}$ and Kimberg, ${ }^{31}$ who addressed this issue most comprehensively, were unable to give specific recommendations but stressed the need to be familiar with local laws and clinic policies. If no policies exist, then Ganley ${ }^{30}$ stressed the need to develop them. Legal departments, state medical societies, and local experts in IPV can be consulted to clarify local reporting responsibilities.

In situations where there is not a clear safety issue that requires reaching out to the victim, the Family Violence Prevention Fund pilot guidelines $^{31}$ recommended that physicians request permission from the perpetrator to contact the victim to provide safety information, but this is not discussed in any other references except for Gondolf, ${ }^{38}$ who, when discussing this for mental health providers, states that their reaching out to the victim can result in possible retaliatory violence on the part of the abuser. Hence, physicians should seek counsel with someone with expertise in IPV before attempting to reach out to the victim.

Providing safety for the victim becomes more complicated when the physician is providing care for both the victim and abuser. ${ }^{31,33,35,36}$ Possible problems that may arise include, but are not limited to, increased risk of violence directed at the victim if the physician inadvertently discloses private information to the perpetrator or the perpetrator becomes emboldened and increases his violence because the physician fails to address it in an appropriate manner. If caring for both the victim and perpetrator, maintaining confidentiality is critical and the physician's care must not be influenced by the abuser's minimizing of the violence. The Royal Australian College of General Practitioners does not recommend that the same physician care for both victim and perpetrator, ${ }^{33}$ whereas other experts believe that it can be done if proper precautions are taken. ${ }^{36}$ If caring for both the victim and the perpetrator, the physician should consult with an IPV expert to determine if one member of the couple should be referred to another physician and, if so, how best to proceed with the referral.

\section{Time Outs and De-Escalation Strategies}

Physicians might explore options with IPV perpetrators that could help them refrain from the harmful behaviors while they await more comprehensive treatment ${ }^{30,31,38}$, ideally from an abuse intervention program or BIP, as discussed below. In the interim and with proper precautions, techniques such as taking "time outs," which temporarily separate an abuser from the victim in times of crisis and are often used in BIPs, may help decrease the abusive behavior while the patient pursues more 
comprehensive care. ${ }^{30,31,38}$ Dobash et $\mathrm{al}^{54}$ recognize the contribution that violence-avoidance strategies have in reducing physical violence, but there is a lack of evidence that these strategies have an impact on emotional or sexual abuse. ${ }^{55}$ In addition, they are untested in the primary care settings, and prior studies have shown that physicians have difficulty determining whether or when couples should separate. ${ }^{29,56}$ Hence, for these reasons as well, there is need for physicians to collaborate with an IPV expert to help craft such strategies.

\section{Referrals}

\section{Batterer Intervention Programs}

Expert guidelines consistently state that BIPs are the best resource to which to refer men who perpetrate IPV..$^{30,31,33-35,37-39}$ BIPs generally use a group approach, are at least 24 weeks in duration, provide education rather than psychotherapy, and have consistent procedures for assessing dangerousness and protecting victims. ${ }^{37,38}$ It should be noted that such programs often do not refer to themselves as "batterer intervention programs" because of the potentially negative associations of the term. The state of Massachusetts, for instance, has changed the name of such programs to "Intimate Partner Abuse Education Programs," and individual programs may use names that do not contain any specific reference to IPV perpetration, focusing instead on healthy relationships. This may help reduce the negative associations patients experience when thinking about going to a BIP. Local domestic violence programs that work with victims may be the best resource for locating such programs if the provider is unfamiliar with them. ${ }^{37,38}$

Although some studies have questioned the effectiveness of $\mathrm{BIPs}^{57,58}$, other studies have found BIPs effective in reducing IPV perpetration. ${ }^{49,59,60}$ The variation in these findings may be related to the variation in BIPs themselves, as well as to the difficulty in measuring rates of IPV perpetration and in assessing completion of a BIP program, the latter of which is often impacted by factors such as history of incarceration, substance abuse, and employment status. ${ }^{60}$ Aldorondo ${ }^{60}$ found that if one controls for completion of BIPs or looks specifically at randomized controlled experiments, then BIPs are associated with a significant reduction in the rates of IPV perpetration.

\section{Substance Abuse and Mental Health}

In addition to attending BIPs, men should also receive appropriate referrals and treatment for substance abuse or mental health problems if these are co-occurring problems. ${ }^{31,33-38}$ This treatment will likely require a separate referral, although there is increased research that explores combining substance abuse therapy with a BIP as part of a comprehensive program. ${ }^{45}$ Hagerty et $\mathrm{al}^{35}$ maintain that if a man is unwilling to accept a referral to a BIP, then a referral he will accept to address either substance abuse or mental health issues may be a helpful start. Ideally, the mental health or substance abuse provider should also be trained to address issues related to IPV, and physicians should not assume that a particular mental health provider is trained to handle domestic violence cases any more than they would assume a general practitioner has expertise in treating cancer. ${ }^{37}$ Hence, physicians should consider contacting their local domestic violence programs or BIPs for suggestions about local mental health providers with expertise in both IPV and comorbid mental health and/or substance abuse issues.

Experts in domestic violence strongly advise against referring a couple in an abusive relationship to couples therapy, unless the therapist has special training in IPV or the batterer has stopped committing violence. ${ }^{30,33,34,36-39}$ Reasons to avoid referring to couples therapy include, but are not limited to, its potential to place the victim at further risk for abuse should she disclose or discuss her partner's abuse to the therapist or it may reinforce the perpetrator's perception that his partner is responsible for his violence or somehow shares responsibility for ending it.

\section{Motivational Interviewing}

Motivational interviewing has been suggested as an intervention for perpetrators of IPV who are not yet ready to accept referrals to a BIP. ${ }^{35}$ Motivational interviewing is defined as a goal-oriented, client-centered counseling style for eliciting behavior change by helping clients to explore and resolve ambivalence. ${ }^{61}$ It is a form of "brief intervention," referring to a patient-health care provider interaction that lasts from 5 minutes to 30 minutes during a clinical session. ${ }^{62}$ For those men not ready to change their behavior, a brief motivational interviewing session in the clinical setting may be a way 
of moving them closer to doing so. An example of motivational interviewing could involve asking the patient, "On a scale of 1 to 10 , where 1 is not at all ready and 10 is extremely ready, how ready are you to seek help for your violence?" If, for example, the patient replies " 3 ," the provider might say, "And why do you say 3 and not a 2?" This allows the patient an opportunity to give his own reasons for making changes.

For those men ready to accept a referral to BIPs, research has shown that brief motivational interviewing improved attendance and treatment compliance among men enrolled in BIPs. ${ }^{63,64}$ Although brief motivational interviewing to address adolescent dating abuse has been explored in the emergency department setting, ${ }^{65,66}$ to our knowledge, brief motivational interviewing to address perpetration of IPV in primary care settings has yet to be explored.

\section{Regular Follow-Up}

Abusive behavior does not resolve after a single intervention; hence, it is recommended that there be regular follow-up with the male perpetrator to continue to support the man's acceptance of referral to a BIP, to provide ongoing education, to monitor the impact of IPV perpetration on the abuser's health, and to monitor for safety. ${ }^{30,31,33,35}$

\section{Future Research}

There is a general paucity of research exploring the role of the health care system in addressing IPV perpetration. Research is needed to explore whether validated screening tools would be helpful, as well as to explore the potential negative impact of screening for IPV perpetration, specifically in terms of the impact on victims of IPV and on physician-patient relations. In addition, research is needed to better understand the health impact of IPV on the perpetrator and to learn what specific teaching points would be most useful for changing a perpetrator's behavior. Further research is also needed to explore interventions for IPV perpetration in the primary care setting, including the possible role of brief motivational interviewing. Physicians also need clear guidance about mandated reporting and how to handle situations when they are caring for both the victim and abuser.

\section{Conclusions}

Physicians need to be aware that their male patients may be perpetrators of IPV. If a male patient dis- closes IPV perpetration, physicians should assess for lethality, impact of violence on the health of the family, readiness to change, and comorbid medical conditions that could impact treatment, such as substance abuse and mental illness. Experts agree that referrals to a BIP should be the primary intervention. If there are no locally available BIPs, or the patient is unwilling to go, then a physician should refer the abuser to a therapist who has been trained specifically to work with IPV perpetrators. In addition, physicians should be prepared to offer education about the negative impact of IPV on the victim, on any children, and on the abuser himself. Physicians should address any untreated substance abuse or mental health issues. Referral to couples therapy should generally be avoided. Physicians should continue to have regular follow-up with their male patients to support them in changing their behavior. Further research is needed to assess the role the health care system can have in preventing IPV perpetration.

To see this article online, please go to: bttp://jabfm.org/content/ 31/4/635.full.

\section{References}

1. Breiding MJ, Basile KC, Smith SG, Black MC, Mahendra RR. Intimate partner violence surveillance: uniform definitions and recommended data elements, version 2.0. Atlanta, GA: National Center for Injury Prevention and Control, Centers for Disease Control and Prevention; 2015.

2. Dobash RE, Dobash RP. Violence against wives: a case against the patriarchy. New York, NY: Free Press; 1979.

3. Straus MA. Wife beating: how common and why? Victimology 1977;2:443-58.

4. Mihalic SW, Elliott D. A social learning theory model of marital violence. J Fam Violence 1997;12:21-47.

5. Heise L. Violence against women: an integrated, ecological framework. Violence Against Women 1998;4:262-90.

6. Hyde-Nolan ME, Juliao T. Theoretical basis for family violence. In R. S. Fife, Schrager S, editors. Family violence: what health care providers need to know. Sudbury, MA: Jones \& Bartlett Learning; 2012. P. 5-16.

7. Bell KM, Naugle AE. Intimate partner violence theoretical considerations: Moving towards a contextual framework. Clin Psychol Rev 2008;28:1096-107.

8. Rodriguez-Menes J, \& Safranoff A. Violence against women in intimate relations: a contrast of five theories. Eur J Criminol 2012;9:584-602.

9. Breiding MJ, Smith SG, Basile KC, Walters ML, Chen J, Merrick MT. Prevalence and characteristics of sexual violence, stalking, and intimate partner violence victim- 
ization- National Intimate Partner and Sexual Violence Survey, United States, 2011. MMWR Morb Mortal Wkly Rep 2014;63:1-18.

10. Catalano, S. Intimate partner violence in the United States. Washington, DC: US Department of Justice, Bureau of Justice Statistics; 2007. Available from: http://www.bjs.gov/content/pub/pdf/ipvus.pdf. Accessed June 18, 2017.

11. Max W, Rice DP, Finkelstein E, Bardwell RA, Leadbetter $\mathrm{S}$. The economic toll of intimate partner violence against women in the United States. Violence Vict 2004;19:259-72.

12. Hamby S, Finkelhor D, Turner H, Ormrod R. Children's exposure to intimate partner violence and other family violence. National Survey of Children's Exposure to Violence. Juvenile Justice Bulletin. Published October 2011.

13. Campbell JC. Health consequences of intimate partner violence. Lancet 2002;359:1331-6.

14. Coker AL, Davis KE, Arias I, et al. Physical and mental health effects of intimate partner violence for men and women. Am J Preventive Med 2002;23: 260-8.

15. Bair-Merritt M, Blackstone M, Feudtner C. Physical health outcomes of childhood exposure to intimate partner violence: a systematic review. Pediatrics 2006;117:e278-90.

16. Felitti VJ, Anda RF, Nordenberg D, et al. Relationship of childhood abuse and household dysfunction to many of the leading causes of death in adults. The Adverse Childhood Experiences (ACE) Study. Am J Prev Med 1998;14:245-58.

17. Holt S, Buckley H, Whelan S. The Impact of exposure to domestic violence on children and young people: a review of the literature. Child Abuse Negl 2008;32:797-810.

18. Lewis-O'Connor A, Sharpe SW, Humphreys J, Faye FA, Campbell J. Children exposed to intimate partner violence. In Feerick M, Silverman G, editors. Children Exposed to Violence. Baltimore, MD: Paul H. Brookes Publishing Co.; 2008. P. 3-28.

19. Walker DD, Neighbors C, Mbilinyi LF, et al. Evaluating the impact of intimate partner violence on the perpetrator: the perceived consequences of domestic violence wuestionnaire. J Interpers Violence 2012; 25:1684-98.

20. Gerlock AA. Health impact of domestic violence. Issues Ment Health Nurse 1999;20:373-85.

21. el-Bassel N, Fontdevila J, Gilbert L, Voisin D, Richman BL, Pitchell P. HIV risks in men in methadone maintenance treatment programs who abuse their intimate partners: a forgotten issue. J Subst Abuse 2001;13:29-43.

22. Moyer VA, on behalf of the U.S. Preventive Services Task Force. Screening for intimate partner violence and abuse of elderly and vulnerable adults: U.S. Preventive Services Task Force recommendation statement. Ann Intern Med. 2013;158:478-86.
23. Catalano S, Smith E, Snyder H, Rand M. Female victims of violence. Bureau of Justice Statistics selected finding. Location: U.S. Department of Justice. Published 2009. Available from: https://www. bjs.gov/content/pub/pdf/fvv.pdf. Accessed June 1, 2018.

24. Jaeger JR, Spielman D, Cronholm P, Applebaum S, Holmes WC. Screening male primary care patients for intimate partner violence perpetration. J Gen Inter Med 2008;23:1152-6.

25. Emst A, Weiss S, Morgan-Edwards S, et al. Derivation and validation of a short emergency department screening tool for perpetrators of intimate partner violence: the Perpetrator Rapid Scale (PERPS). J Emerg Med. 2012;42:206-17.

26. Oriel KA, Fleming MF. Screening men for partner violence in a primary care setting. A new strategy for detecting domestic violence. J Fam Pract 1998;46: 493-8.

27. Burge SK, Schneider FD, Ivy L, Catala S. Patients' advice to physicians about intervening in family conflict. Ann Fam Med 2005;3:248-54.

28. Singh V, Tolman R, Walton R, Chermack S, Cunningham $\mathrm{R}$. Characteristics of men who perpetrate intimate partner violence. J Am Board Fam Med 2014;27661-668.

29. Penti B, Tran H, Timmons J, Rothman EF, Wilkinson J. Physicians' experiences with male patients who perpetrate intimate partner violence. J Am Board Fam Med 2017;30:239-247.

30. Ganley A. Health care responses to perpetrators of domestic violence. In: Ganley A, Warshaw C, editors. Improving the health care response to violence: a resource manual for health care providers. San Francisco, CA: Family Violence Prevention Fund; 1998.

31. Kimberg LS. Addressing intimate partner violence with male patients: a review and introduction of pilot guidelines. J Gen Intern Med 2008;23:2071-8.

32. American Academy of Family Physicians. Violence Position Paper. Available from: www.aafp.org/ about/policies/all/violence.html. Published 2014. Accessed Nov 26, 2016.

33. Royal Australian College of General Practitioners. Abuse and violence: working with our patients in general practice (4th ed.). Melbourne, Australia: The Royal Australian College of General Practitioners; 2014. Available from: http://www.racgp.org.au/yourpractice/guidelines/whitebook/chapter-5-dealingwith-perpetrators-in-clinical-practice/. Published. Accessed October 22, 2017.

34. Cronholm PF. Intimate partner violence and men's health. Prim Care 2006;33:199-209.

35. Hegarty K, Forsdike-Young K, Tarzia L, Schweitzer $\mathrm{R}$, Vlais R. Identifying and responding to men who use violence in their intimate relationships. Aust Fam Physician 2016;45:176-81.

36. Ferris LE, Norton PG, Dunn EV, Gort EH, Degani N. Guidelines for managing domestic abuse when 
male and female partners are patients of the same physician. JAMA 1997;278:851-7.

37. Adams D. Guidelines for doctors on identifying and helping their patients who batter. J Am Med Womens Assoc 1996;51:123-6.

38. Gondolf E. Identifying and assessing men who batter. In: Assessing woman battering in mental health services. Thousand Oakes, CA: Sage Publications; 1998. P. 132-156.

39. Mintz HA, Cornett FW. When your patient is a batterer. Postgrad Med 1997;101:219-28.

40. Taft C, Schwartz S, Liebshutz JM. Intimate partner aggression perpetration in primary care chronic pain patients. Violence Vict 2010;25:649-61.

41. Areán CA. Fathering after violence. Family Violence Prevention Fund; 2008. Available from: https://www. futureswithoutviolence.org/userfiles/file/Children and_Families/fathering_after_violence.pdf. Accessed June 1, 2018.

42. Håland K, Lundgren I, Lidén E, Eri TS. Fathers' experiences of being in change during pregnancy and early parenthood in a context of intimate partner violence. Int J Qual Stud Health Well-being 2016,11:30935.

43. Veteläinen A, Grönholm H, Holma J. Discussions of fatherhood in male batterer treatment group. SAGE Open. 2013;3:1-10.

44. Stover CS. Fathers for change: a new approach to working with fathers who perpetrate intimate partner violence. J Am Acad Psychiatry Law 2013; 41:65-71.

45. Bennett, L, Bland P. Substance abuse and intimate partner violence. Harrisburg, PA: VAWnet, a project of the National Resource Center on Domestic Violence/Pennsylvania Coalition against domestic violence. Available from: http://www.vawnet.org. Published May 2008. Accessed October 20, 2017.

46. Rhodes KV, Houry D, Cerulli C, Straus H, Kaslow $\mathrm{NJ}, \mathrm{McNutt} \mathrm{L}$. Intimate partner violence and comorbid mental health conditions among urban male patients. Ann Fam Med 2009;7:47-55.

47. Danielson KK, Moffitt TE, Caspi A, Silva PA. Comorbidity between abuse of an adult and DSM-III-R mental disorders: evidence from an epidemiological study. Am J Psychiatry 1998;155:131-3.

48. Shorey RC, Febres J, Brasfield H, Stuart GL. The prevalence of mental health problems in men arrested for domestic violence. J Fam Violence. 2012; 27:741-8.

49. Jones AS, Gondolf EW. Time-varying risk factors for reassault among batterer program participants. J Fam Violence 2001;16:345-59.

50. Jouriles EN, O'Leary KD. Interpersonal reliability of reports of martial violence. J Consult Clin Psychol 1985;53:419-21.

51. Edleson JL, Syers M. Gender differences in reporting of battering incidences. Fam Relat 1990;35:377-82.
52. Campbell JC, Webster DW, Glass N. The danger assessment. Validation of a lethality risk assessment instrument for intimate partner femicide. J Interpers Violence 2009;24:653-74.

53. Iwi K, Newman C. Domestic violence: engaging with perpetrators of domestic violence: practical techniques for early intervention. London: Jessica Kingsley Publishers; 2015.

54. Dobash RE, Dobash RP, Cavanagh K, \& Lewis R. Changing violent men. Thousand Oaks, CA: Sage; 2000.

55. Wistow R, Kelly L, Westmarland N. "Time out": a strategy for reducing men's violence against women in relationships? Violence Against Women. 2017;23:730-48.

56. Herbert CP. Family violence and family physicians: opportunity and obligation. Can Fam Physician 1991;37:385-90.

57. Babcock JC, Green CE, Robie C. Does batterers' treatment work? A meta-analytic review of domestic violence treatment. Clinical Psych Review 2004;23:1023-53.

58. Eckhardt CI, Murphy C, Black D, Suhr L. Intervention programs for perpetrators of intimate partner violence: conclusions from a clinical research perspective. Public Health Rep 2006;121:369-81.

59. Tolman RM, Bennet LW. A review of quantitative research on men who batter. J Interpers Violence 1990;5:87-118.

60. Aldarondo E. Discussion paper presented at Batterer Intervention: Doing the work and measuring the progress, National Institute of Justice, U.S Department of Justice and the Family Violence Prevention Fund with the support of "The Woods" Charitable Foundation, Bethesda, MD; 2009.

61. Miller WR, Rollnick S. Motivational interviewing, preparing people to change addictive behavior. New York: The Guildford Press; 1991.

62. SAMHSA. SBIRT: brief intervention. Available from: http://www.integration.samhsa.gov/clinicalpractice/sbirt/brief-interventions. Published 2015. Accessed July 11, 2017.

63. Crane CA, CI Eckhardt. Evaluation of a singlesession brief motivational enhancement intervention for partner abusive men. J Counseling Psych 2013; 60:180-87.

64. Kistenmacher BR, Weiss RL. Motivational interviewing as a mechanism for change in men who batter: a randomized controlled trial. Violence Vict 2008;23:558-70.

65. Rothman EF, Wang N. A feasibility test of a brief motivational interview intervention to reduce dating abuse perpetration in a hospital setting. Psychol Violence 2016;6:433-41.

66. Cunningham RM, Whiteside LK, Chermack ST, et al. Dating violence: outcomes following a brief motivational interviewing intervention among at-risk adolescents in an urban emergency department. Acad Emerg Med 2013;20:562-9. 